\title{
Maniace Castle in Syracuse, Italy: Comparison Between Present Structural Situation and Hypothetical Original Configuration by Means of Full 3D FE Models
}

\author{
Siro Casolo, Gabriele Milani ${ }^{*}$, Carlo Alberto Sanjust and Alberto Taliercio
}

Dipartimento di Ingegneria Strutturale (DIS), Politecnico di Milano, Piazza Leonardo da Vinci 32, 20133 Milan, Italy

\begin{abstract}
The Maniace Castle in Syracuse, Italy, built under Emperor Frederick II in the first half of the 13th century, is analyzed from a structural point of view by means of a detailed 3D Finite Element model. The castle was struck by many catastrophic events during the centuries, which heavily damaged the structure and caused subsequent changes in the original implant.

After a concise description of the main architectural characteristics of the building and its actual state of degradation, two full 3D FE numerical analyses are discussed, representing respectively the present geometric configuration and that obtained after a hypothetical intervention aimed at reporting the structure into its original conceived shape. Conventional static analyses in the linear range are performed on such large scale meshes, under gravity loads and horizontal loads conventionally representing seismic excitation, respectively investigating the role played by self-weight into the degradation of some structural elements (particularly central columns of the hypostyle hall) and the effect induced by horizontal forces on both the global behavior and the local widespread local regions with positive stresses. On the basis of such numerical results, some useful observations to be considered in a future plan of restoration aimed at reporting the castle in its original configuration are finally provided.
\end{abstract}

Keywords: Masonry, full 3D FE analyses, case study, seismic actions, gravity loads.

\section{INTRODUCTION}

The Maniace Castle stands on the tip of the island of Ortigia (Syracuse), where it was built in the first half of the XIII century by Frederick II's trusty architect, Richard of Lentini, who also designed Ursino Castle in Catania. Built of sandstone blocks joined by thin mortar, it owes its name to the Byzantine general who besieged and took Ortigia from the Arabs in 1038.

Although it was badly damaged by the earthquake that devastated the southeast of Sicily in 1693, giving rise to numerous reconstructions in baroque style, it still conserves its characteristic $13^{\text {th }}$ century structure - i.e. a square plan, with four cylindrical towers at the sides, Fig. (1) The castle is reached by way of a stone bridge. The imposing main door, with its pointed arch of Islamic inspiration is covered in polychrome marble and surmounted by the imperial coat of arms of Charles V, with niches on either side that used to contain two bronze rams of Hellenistic age.

In the original configuration, the inner structure presented a single big hypostyle hall ("Salone") covered by twenty-five cross vaults supported by slender columns, Fig. (2), with a monumental fireplace in each of the four corners. During the

*Address correspondence to this author at the Department of Structural Engineering, Technical University of Milan, Piazza Leonardo da Vinci 32 20133 Milan Itali; Tel: +39 349 5516064; Fax: +39 (0)532 807130;

E-mails: milani@stru.polimi.it, gabriele.milani@polimi.it 16th century the castle was surrounded by a ring of bastions. Today, thanks to restoration and consolidation work on the entire belt of fortifications, it is possible to visit exhibitions and enjoy cultural events in the evocative scenario of the Parade Ground.

During its long lifetime, earthquakes have been a cause of damage for the castle. The main known seismic events that have struck the castle are reported in Table 1 . The corresponding Mercalli-Cancani-Sieberg intensity scale is also reported. The military use of the castle also caused major damage to the structure. Indeed, a few years after the earthquake of 1693, in November 1704, a lightning struck the castle during a storm and a huge explosion of the ammunition dump completely destroyed $3 / 5$ of the vaulted hall which had never been rebuilt in its original shape. Other minor changes were made in 15th, 16th and 17th centuries. Presently, only two spans of the original "Salone" survive on the S-E side. A plan and two sections of the castle as it appears now are sketched in Fig. (3).

In recent years, the deterioration of some elements of the building has caused concern for its structural safety when subjected to a possible seismic event. In particular, the remaining four central columns of the hypostyle hall present a number of vertical cracks, clearly suggesting that these elements are subjected to severe compression conditions.

As a consequence, steel hoops have been provisionally installed on the drums and on the capitals, as shown in the 


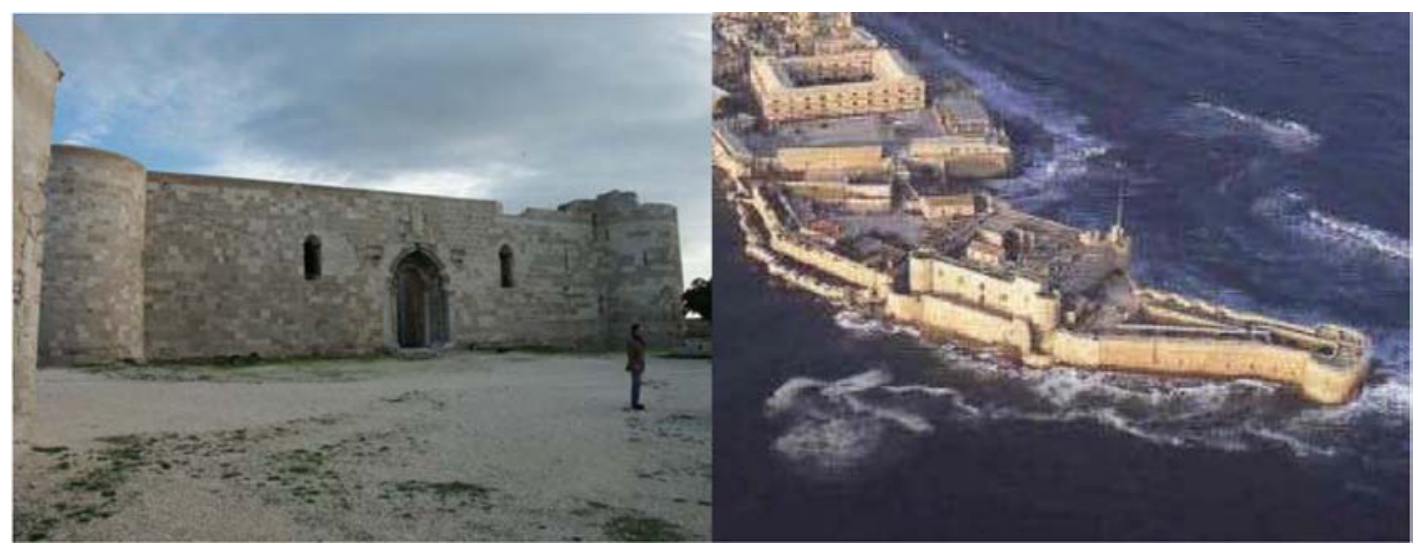

Fig. (1). Perspective view of the Maniace Castle and aerial photo.

Table 1. Earthquakes with Local Intensity Is $>5.0$ Registered in Syracuse

\begin{tabular}{|c|c|c|}
\hline Date (dd/mm/yyyy) & Epicentral zone & Is (MCS) \\
\hline \hline $11 / 01 / 1693$ & East Sicily & 5.0 \\
\hline $15 / 06 / 1717$ & Syracuse & 5.5 \\
\hline $20 / 02 / 1818$ & Catania & 6.0 \\
\hline $11 / 01 / 1848$ & Augusta & 5.5 \\
\hline $11 / 09 / 1934$ & Madonie montains & 5.0 \\
\hline
\end{tabular}

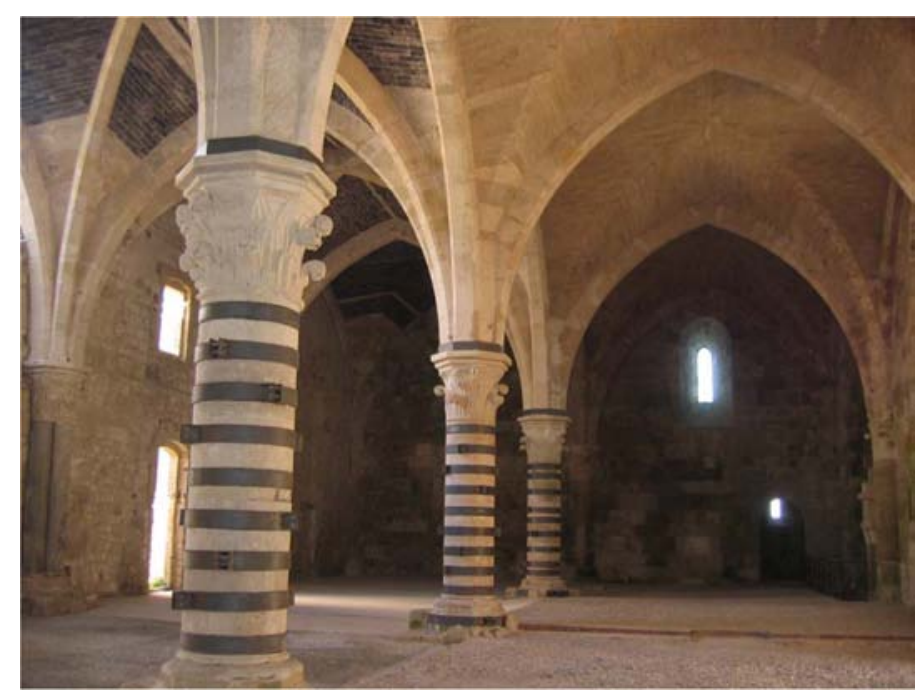

Fig. (2). Steel hoops on columns of the hypostyle hall.

photo of the interior hypostyle hall reported in Fig. (2). While this solution appears architectonically debatable, it is probably the only one possible, except a technically more difficult strengthening obtained by injection grouting.

The Superintendence of Cultural and Environmental Heritage of Syracuse (Soprintendenza ai Beni Culturali ed Ambientali di Siracusa), in the last two decades, has planned a series of scientific studies to investigate the safety of the Castle, as well as other main monuments, with regards to the simple static actions due to weight, as well as against the occurrence of seismic actions [1-6]. More recently, in collaboration with the Politecnico di Milano an innovative study was directed toward the exploration of a possible scenario which assumes the reconstruction of the entire hall in its original configuration [7], i.e. consisting of the full reconstruction of the internal vaults on all sides, after the pull down of the existing internal walls and rooms, as indicated in Fig. (3), on the right side.

In the meantime, in order to have a better insight into the sustainability of the most urgent intervention, a number of studies and diagnostic investigations on the structure have been commissioned. First studies go back to 1999, when ISMES [1] carried out some in situ experimental tests, as flat jack measurements, identification of principal vibrating modes and frequencies, georadar analysis of the ground and probing of the walls. Experimental vibrating frequencies to 

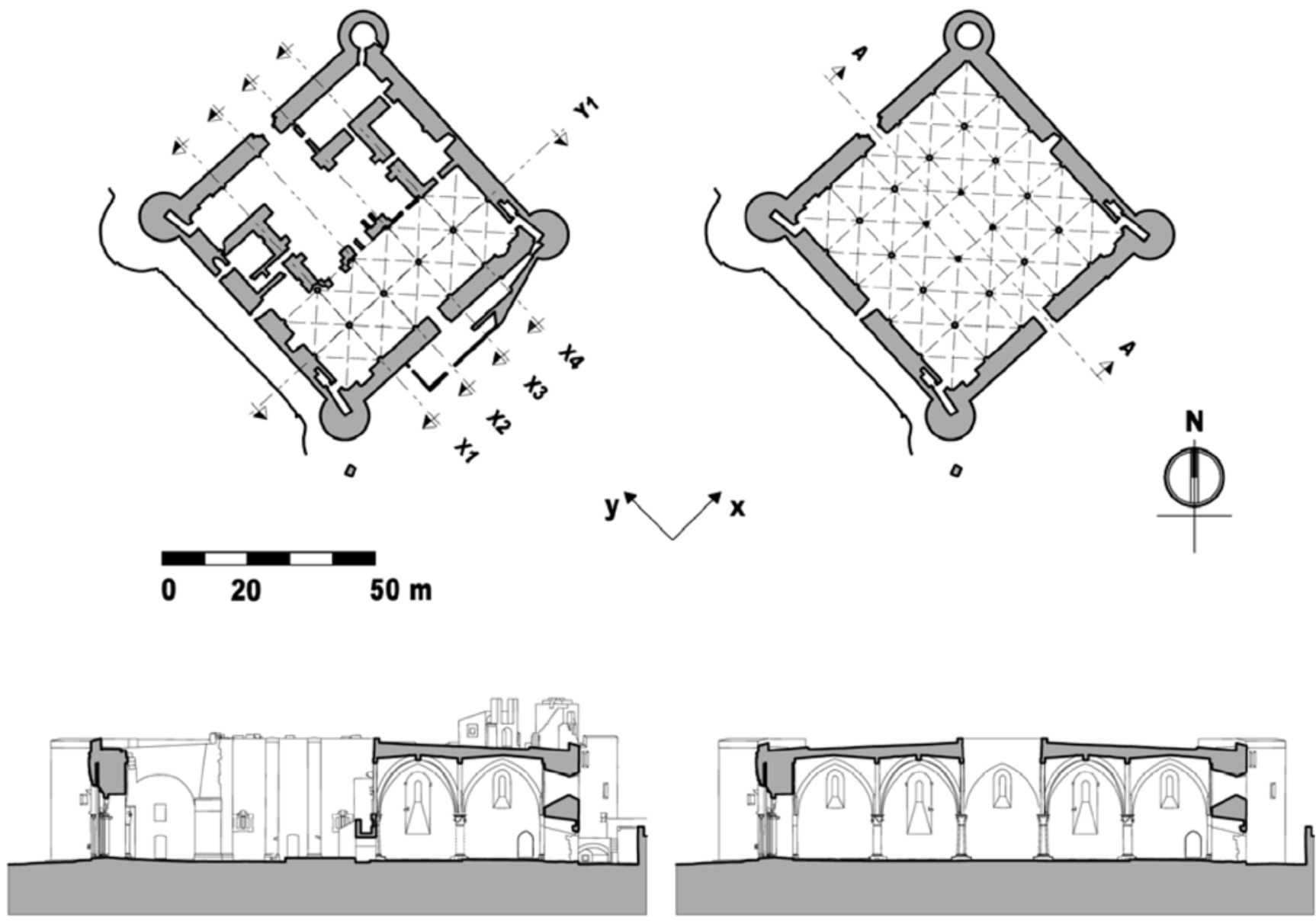

\section{0}

20 $50 \mathbf{m}$

Fig. (3). Plan and longitudinal sections of the castle, with identification of the sections where stresses patches will be plotted. Left: present configuration. Right: hypothetic reconstruction of the original configuration.

Table 2. Measured and Calculated Frequencies of the First Four Natural Modes.

\begin{tabular}{|c|c|c|c|c|}
\hline Mode & ISMES measures [Hz] [1] & University of Padua [2] [Hz] & Casolo and Sanjust [6] [Hz] & Present 3D model [Hz] \\
\hline \hline 1 & 5.16 & 5.40 & 5.78 & 5.99 \\
\hline 2 & 9.55 & 8.90 & 8.08 & 7.02 \\
\hline 3 & 9.58 & 10.1 & 8.81 & 7.71 \\
\hline 4 & 10.6 & 10.4 & 9.03 & 9.05 \\
\hline
\end{tabular}

compare with numerical data are reported in Table 2. Later, a global 3D FE model of the whole castle within the commercial code Strand 7 was made by Modena et al. [2] and, using a rough discretization within ABAQUS, by Casolo and Sanjust [4,6]. In 2003, based on Modena et al. [2] numerical results, a new diagnostic investigation focused on the ultrasonic analysis of the columns was made by Ipertec [3]. At the same time, the Soprintendenza also made a request to the Politecnico di Milano for a more detailed numerical determination of the local stress conditions in the columns and in the arches of the hypostyle hall when subjected to seismic loads.
The research presented in this paper, on one hand is inspired by the suggestion concerning a hypothetical restoration of the entire hypostyle hall, as a whole. On the other hand, it is of great scientific interest, as part of the study relating to the history of this monument, to see how it withstood the catastrophic events, and mainly a number of large earthquake during the centuries, due to its unique and original structural form.

The approach is fully numerical and provides an insight, from a structural point of view, on the seismic performance of the castle as it is and after its hypothetical modification towards its original configuration. To this aim, two full 3D 
FE models built within the commercial code ABAQUS [8] are utilized in the linear range. The static analyses under gravity loads are preliminary performed, similarly to what was done in [9], in order to quantitatively evaluate the state of compression of the main vertical structural elements - e.g. the columns of the hypostyle hall - which exhibits visible cracks, and the areas of the vaults undergoing positive principal deformation. The identification of positive principal plastic deformation zones is important, by giving a preliminary insight into the propagation of cracks for tensile actions, since the masonry behavior is well approximated assuming for it scarcely resistant orthotropic material models [10]. Although a linear elastic analysis is of course inaccurate for masonry, which exhibits a non-linear behavior at very low levels of external actions, it remains a standard approach in common practice (see e.g. Italian codes [11]) and in the presence of complex structures where it is impossible to reduce it to an equivalent frame $[12,13]$. In addition, elastic analyses are preliminarily useful to identify the possible zones where damage may occur, in light of sophisticated analyses to perform on isolated structural elements.

Eigenvalue analyses are also conducted on both models, to compare with existing experimental data and with each other. Finally elastic analyses under horizontal loads (conventionally representing a seismic action) are conducted and results are critically discussed and compared. Lateral acceleration applied is equal to $2.5 \mathrm{~m} / \mathrm{sec}^{2}$, which corresponds to the design ground acceleration $a_{-} \mathrm{g}=0.25 \mathrm{~g}$, for rock soil (type A according to Eurocode 8 ) and a return period $T=475$ years, as provided by the former Italian sesmic code (O.P.C.M. 3274) [14] for seismic zone 2. It is worth noting however that this value of acceleration has no meaning in terms of seismic verification, but it is olny functional to obtain a meaningful picture of the internal stresses in the event of an earthquake of high destructive potential. It will be shown how the model of the castle representing the original hypothetic configuration exhibits a quite different global behavior and how local interventions aimed at a seismic vulnerability reduction of some structural elements would be beneficial.

\section{EVALUATION OF THE DEGRADATION OF THE STRUCTURAL ELEMENTS}

Modena and co-workers [2] collected an exhaustive series of investigations regarding some structural elements in elevation, acquiring metrical and compositional information by mechanical surveys of continuous core sampling and subsequent inspection of the boreholes with a color television probe. In addition, the state of stress and the deformability characteristics through tests with flat jacks were determined, accompanied by a study of texture uniformity by geophysical and radar analyses. Thanks to the core samplings, different wall textures probably belonging to different building periods were identified, ranging from masonry mainly characterized by mortar of poor consistence -low percentage of binder- and very low adherence, to masonry with strong mortar cohering well with the stone elements. The variability along the thickness was inspected by means of the television probe.

Flat jack tests were useful to estimate vertical compression stress and elastic moduli. North and west towers are characterized by similar stress values, around $0.31 \mathrm{MPa}$, whereas load eccentricities in the east and south towers are responsible for higher values of compression, around $1 \mathrm{MPa}$. Such discrepancy was explained by Modena and co-workers [2] on the basis of the original construction techniques and to probable rotations of the towers. Other discrepancies were found in the internal courtyard, where the value registered on the buttress leaning against the perimeter wall of the main structure that supports the weight of the arches forming the vaults, exhibits a possible rotation towards the courtyard. In the main covered room, the "Salone", divided in two by a series of columns on which the ribs of the cross vaults that constitute the roofing rest, large average values of compression stress (3.75 MPa) were registered. The stairs and other masonry connecting the towers showed low stress values, that are also confirmed in the containing walls of the embankment on the south-west side at sea level.

Perimeter walls of the castle are very thick (1.60 meters) and built using three-leafs. To fully characterize the different typologies of masonry found, Modena et al. [2] also performed double flat jack tests. From tests results, it was found that the brickwork edged in squared stone have relatively high elastic modulus values, equal to 11110 and $10000 \mathrm{MPa}$. Conversely random masonry exhibited a large scatter, having low moduli varying between 900 and $4800 \mathrm{MPa}$, with elastic moduli values for the backfill very low (350 MPa). Tests conducted on masonry of the castle crown, in both the calcareous and lava stone samples, exhibited again a low elastic modulus ranging between 850 and $930 \mathrm{MPa}$, with an estimate of compression strength between 1.20 and 1.60 MPa.

An important and diffused damage pattern was found in some columns, a situation which suggested to perform nondestructive geophysical inspections on two columns of the ground floor belonging to the hypostyle hall. Cross-hole type measurements (sonic and radar) characterised the columns globally, while horizontal sonic tomography detailed the internal constituent conditions limited to the section examined. These investigations confirmed the continuity of the cracking or lack of cohesion inside the columns, while they excluded the presence of voids or extended cavities.

\section{THE THREE-DIMENSIONAL MODEL OF THE WHOLE CASTLE}

Several FE models have been already presented in the literature dealing with the analysis of the Maniace castle, e.g. $[2,4,6]$.

Here a new FE model much more refined in terms of both accuracy of the discretization, materials used and geometric representation is proposed. In addition, the static behavior of the structure after the hypothetical reconstruction of the hypostyle hall on all sides (according with the original plant of the time of Frederick II) is investigated, probably for the first time with this level of accuracy.

In particular, the global behavior of the castle under gravity loads and lateral acceleration is studied by means of two large three-dimensional finite element models: one devoted to the analysis of the present situation, the other dealing with the reconstruction hypothesis, see).

When dealing with the present situation, hereafter labeled as Mesh 1 for the sake of clearness, the 3D discretization as- 
sumed for the numerical simulations is constituted by 32436 solid elements, 51402 nodes and 154206 degrees of freedom. A quite refined mesh was preferred to properly reproduce stress concentrations and the actual shape of some elements, interesting both from a structural and architectural point of view.

Similar considerations may be repeated for the FE model representing the hypothetical configuration, hereafter called Mesh 2, which required obviously the utilization of much more elements, namely 48404 solid elements, 84306 nodes and 252918 degrees of freedom.

Due to the complex geometry of the monument, and to avoid mesh distortion, the castle was modeled in 77 separate parts meshed independently and then assembled in a single model using tie constraints available in ABAQUS [8], a very straightforward pre-processing procedure which allows the utilization of different mesh sizes for coincident surfaces belonging to different volumes. While the mesh is apparently topological incorrect, ties allow to impose interpolated displacements for nodes belonging to the same surface. The hypostyle hall was modeled with quadratic 20-node solid brick elements (named C3D20R into the adopted ABAQUS computer code), whereas 10-node tetrahedral elements (C3D10M) were adopted for the parts of minor interest.
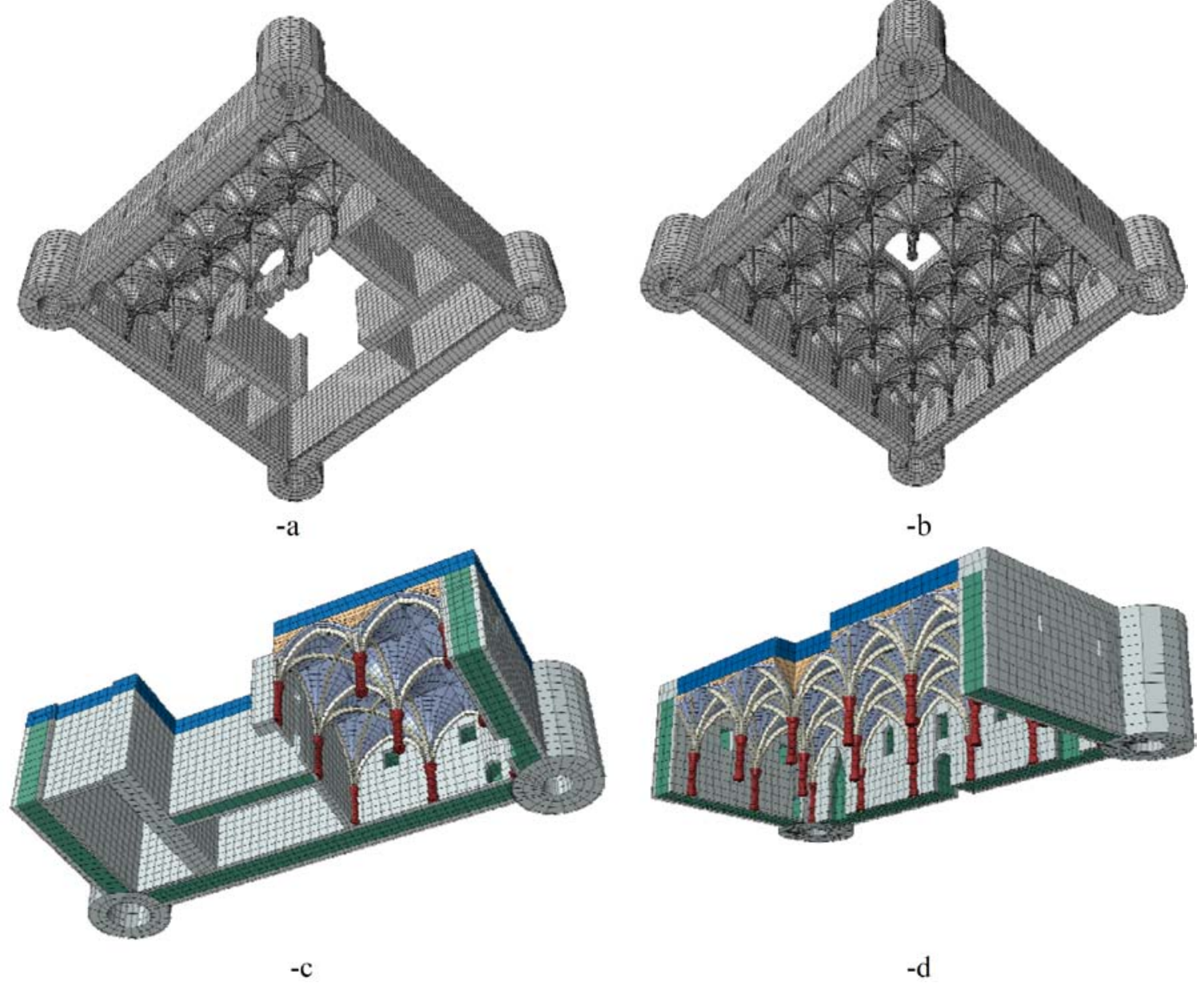

The geometry of this model was slightly simplified by disregarding many architectural details of minor importance, but modeling very accurately both the shape of the internal vaults and the actual geometry of the columns.

Elastic moduli given to the different construction materials are assigned in substantial agreement with the data already published about this building $[2,4,6]$. However, an accurate trial and error calibration on experimental data, to match as close as possible measured frequencies, is adopted in the paper. In particular, some mechanical properties of the constituent materials are changed in a relatively wide range, to investigate how sensible are output eigen-frequencies to input properties (elastic moduli and materials densities). Initial values assigned to the materials stiffness and to the mass density are reported in Table $\mathbf{3}$ (see $\mathbf{- c}$ and $-\mathbf{d}$ ) for a graphical visualization of the different materials used in Mesh 1 and Mesh 2).

On both models, the following numerical simulations were performed:

1) Eigenvalues analyses. Such numerical analysis allows determining the first global eigen-modes and frequencies of the structure, to compare with experimental data in case of the discretization representing the existing structure (mesh 1) and for a numerical comparison be-

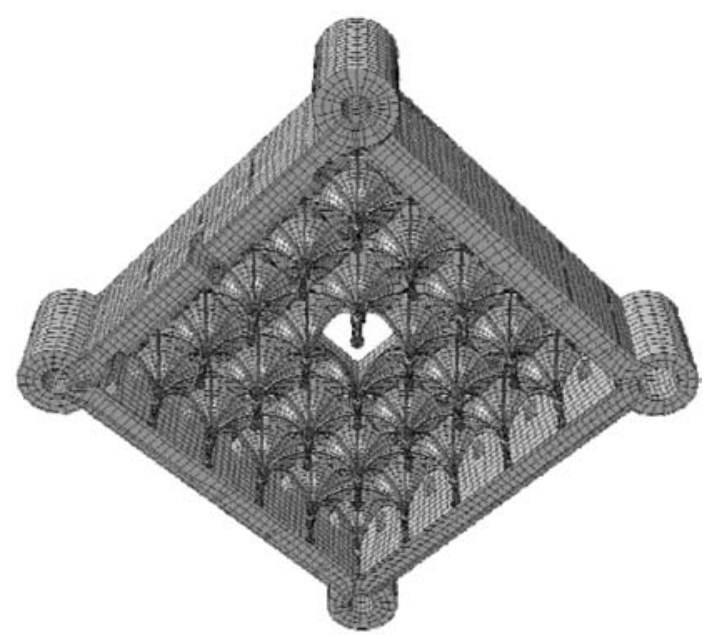

Fig. (4). FE discretization of the castle. -a: present configuration, Mesh 1. -b: hypothetical reconstruction of the original configuration [1], Mesh 2. -c and -d: perspective views of one half of Mesh 1 (left) and Mesh (right). 
Table 3. Mechanical Properties Adopted for the Materials Employed in the Initial Numerical Analyses

\begin{tabular}{|c|c|c|c|}
\hline Architectural elements & Density [Kg/m $\left.{ }^{3}\right]$ & Young Modulus [MPa] & Poisson's ratio [ ] \\
\hline \hline Columns & 2200 & 10000 & 0.1 \\
\hline Arches & 2200 & 10000 & 0.2 \\
\hline Roof of the hypostyle hall & 1000 & 10000 & 0.1 \\
\hline Arches base & 2200 & 400 & 0.1 \\
\hline Vaults infill & 1100 & 4400 & 0.1 \\
\hline Perimeter walls external leafs, towers & 2000 & 1000 & 0.1 \\
\hline Perimeter walls internal leafs & 1800 & 5000 & 0.1 \\
\hline Vaults hypostyle hall & 2000 & 0.1 \\
\hline
\end{tabular}

tween the FE models representing the castle in its present and hypothetical original configuration. A tuning of the elastic moduli is needed in this phase to fit as close as possible experimental frequencies related to the first four eigen-modes.

2) Preliminary elastic analyses for both models subjected to gravity loads only. Such analyses allow a fast estimation of the levels of compression and of the zones which undergo positive principal stress, thus giving indirect information on the possible location of cracks. A comparison between states of stress of the models gives an interesting insight into the most critical structural elements in the present situation and the hypothetical original configuration.

3) Simplified seismic analyses, performed using a value of $2.5 \mathrm{~m} / \mathrm{s}^{2}$ as horizontal acceleration, which corresponds the design ground acceleration $\mathrm{a}_{\mathrm{g}}=0.25 \mathrm{~g}$, as provided by the former Italian sesmic code (O.P.C.M. 3274) [14] for the town of Syracuse. The structural response when dealing with horizontal actions is obviously more complex to interpret with respect to gravity loads. In the framework of a schematization of the seismic excitation with equivalent static loads, relevant horizontal actions must be applied to the model.

As it is well known, masonry exhibits very low tensile strength and non-linearity is reached early at very low levels of external loads, meaning that the most appropriate analysis within the assumption of static loads would be pushover. Pushover is suggested by the Italian code NTC 2008 [11] as one of the possible methods of analysis for a masonry building, however almost always in combination with a schematization of a masonry building by means of the so-called equivalent frame approach, which roughly coincides with the substitution of the actual geometry with an equivalent frame, with plasticization concentrated on hinges exhibiting limited ductility. For historic structures, due to the specificity of the masonry material, the irregularities of construction, the presence of curved structures as vaults and arches and the geometric complexity, such a simplification does not hold. The recent Guide-Lines of the Italian Minister for the Cultural and Architectural Heritage $[15,16]$ suggest in this case either a conventional elastic analysis or a pushover analysis conducted using full 3D discretizations and elasto-plastic or damaging materials. However, this latter approach is hardily applicable for very large scale structures, as the case here treated, being very much time consuming to perform for the non-linear simulations. In addition, while pushover is a global approach where the safety assessment is done on the whole structure reducing the base shear-maximum displacement curve to a 1DOF system, a conventional elastic approach allows a quite accurate insight also into the local state of stress and safety of each single element. In particular, such analysis may highlight the state of expected internal actions that the structure undergoes in presence of the expected seismic event. Numerical results, when coupled with local checks on single structural elements between ultimate and present internal actions, allows a conventional evaluation of the safety of the structure as a whole and of each structural element. For these reasons, a conventional elastic approach is utilized in what follows.

\subsection{Natural frequencies analysis}

To calibrate mechanical properties of the materials belonging to the numerical model to compare with existing data (both experimental and numerical) regarding the free vibration frequencies and modes, full sensitivity analyses were conducted.

Elastic moduli utilized in the first step are those deduced from previous contributions in this field [2, 4], and are summarized in Table 3 . Using such values, a discrepancy - with respect to [6] numerical model - on the first frequency was observed, Table 2, mainly due to the utilization of a numerical model much more refined both in terms of geometry and material specificity, which takes also into account the actual multi-leaf character of the perimeter walls.

On the basis of such results, it is therefore interesting to conduct a parametric study varying Young moduli and density of the materials, subsequently evaluating the changes induced on the global behavior of the structure, especially when dealing with the first four eigen-modes frequencies.

The final aim is to fit experimental measures of natural frequencies as close as possible, eventually imposing for some materials a specific amount of orthotropy (vaults) and varying elements stiffness and dead loads. From authors' experience, it has been concluded that a change of shear elastic 
moduli helps considerably in reproducing experimental evidences.

In Fig. (5) the results of full sensitivity analyses on the first four frequencies of the castle, obtained varying both infill Young and shear modulus as well as density of perimeter walls, are summarized. As it is possible to notice, infill Young modulus has, as expected, a rather marked effect on eigen-frequencies, confirmed by the central plot where the difference between first vs. second and third vs. fourth mode frequencies are represented. Also density of perimeter walls
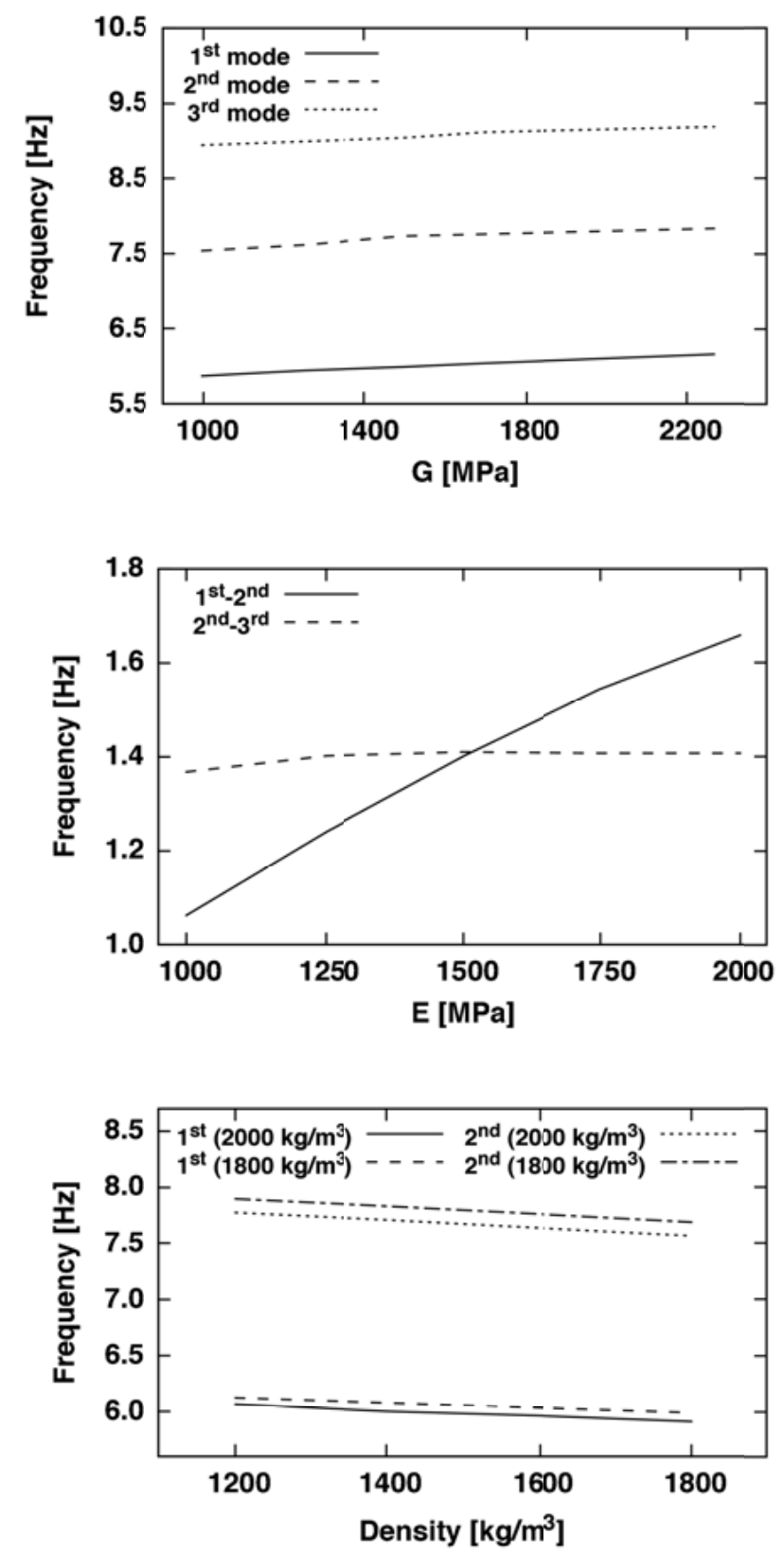

Fig. (5). Top: frequencies of the first three modes varying shear elastic modulus of vaults. Center: differences between frequencies of $1^{\text {st }}-2^{\text {nd }}$ and $2^{\text {nd }}-3^{\text {rd }}$ mode varying shear elastic modulus of the infill of the external walls. Bottom: first two modes frequencies variation at different densities of external walls infill (simulations are replicated for two different densities of the external leafs). plays a quite marked role on the determination of the first two frequencies, as shown in the lower sub-figure.

To conclude, from the huge amount of sensitivity analyses conducted by the authors, the following considerations may be drawn:

- The mechanical properties assigned to hypostyle hall columns have little influence on vibration modes;

- Modes higher than first are strongly influenced by shear modulus;

- Young moduli of perimeter walls (both external leaves and infill) have much more influence on the second vibration mode than on the first.

- When the stiffness of the hypostyle hall is increased, the difference between frequencies associated to the first and second mode increases.

- It is useful to assume an orthotropic behavior of the vaults, decreasing shear modulus independently from axial modulus, kept equal to $5000 \mathrm{MPa}$.

- Shear moduli of the materials belonging to the hypostyle hall influence in the same way the first four vibration modes frequencies.

On the basis of such considerations, mechanical properties adopted for the materials have been re-defined as in table, in order to minimize the gap between present results and experimental data.

When dealing with the existing present configuration, i.e. Mesh 1, results of the natural frequencies analysis (first four modes) are summarized in Fig (6). As it is possible to notice, Mode 1 is mainly flexural and involves a lateral displacement of the roof along the NW-SE direction; mode 2 involves the lateral displacement of the roof along the NE-SW direction, whereas mode 3 involves a meaningful vertical displacement of the roof. Mode 4 is much complex and involves a significant skew-symmetric response of the hypostyle room. Authors experienced that the first five modes are sufficient in the two directions to obtain a coefficient of modal participation of the weight above the minimum required by the Italian Code OPCM 3274 (2003) [14].

The most meaningful aspect of the investigations in the dynamic field, well demonstrated by both the experimental tests and numerical modeling, is that besides the first mode (that involves symmetrical flexural distortions of the masonry structure and that, as expected, gives the most important contribution to the mass participation), third and fourth modes are quite complex, involving in flexion and torsion the hypostyle hall and one of the big external walls. The vaulted system appears, in mode 1 , thus subjected to a coupled torsional and flexural deformation, with meaningful flexural deformations of the columns.

When dealing with Mesh 2 (castle in its hypothetical original configuration) it is worth noting that the first four modes, represented in Fig. (7) with corresponding frequencies, are much more regular (especially mode 3 and 4 ) thanks to the perfect symmetry of the plan. Mode 1 and 2 have almost the same frequency, as expected an obvious consequence of the square geometry of the structure. 


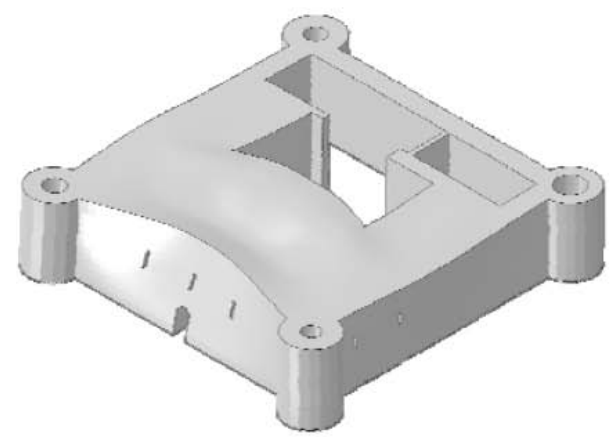

Mode I. Frequency Hz 5.99

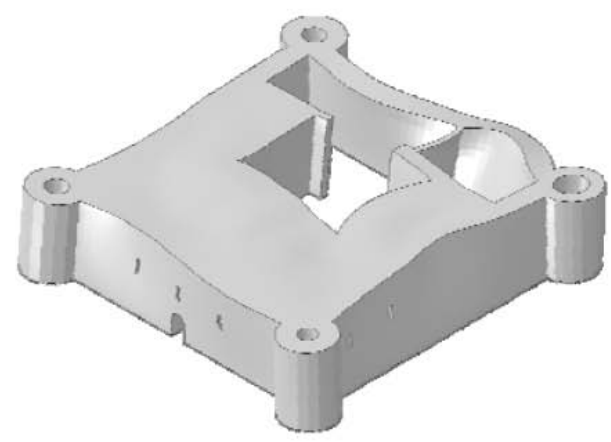

Mode III. Frequency Hz 7.71

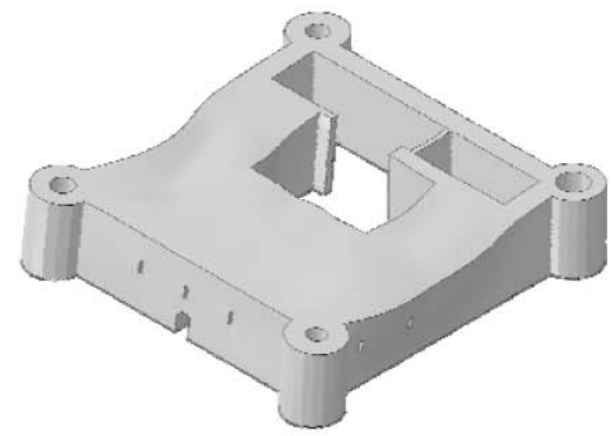

Mode II. Frequency Hz 7.02

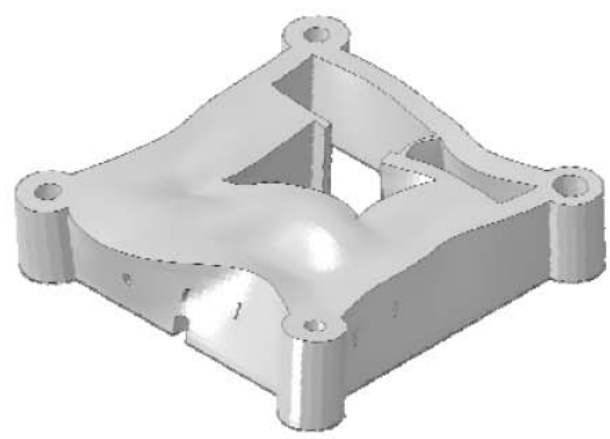

Mode IV. Frequency Hz 9.05

Fig. (6). First four eigen-models and corresponding frequencies. Present configuration.

Table 4. Mechanical Properties Adopted for the Materials Employed in the Numerical Analyses After Tuning of Eigen-frequencies

\begin{tabular}{|c|c|c|c|c|}
\hline Architectural elements & Density $\left[\mathrm{Kg} / \mathrm{m}^{3}\right]$ & $\mathrm{E}_{1}=\mathrm{E}_{2}=\mathrm{E}_{3}$ & $v_{12}=v_{13}=v_{23}$ & $\mathrm{G}_{12}=\mathrm{G}_{13}=\mathrm{G}_{23}$ \\
\hline Columns & 2200 & \multicolumn{3}{|c|}{ Isotropic $\mathrm{E}=10000 v=0.1$} \\
\hline Internal walls & 1800 & \multicolumn{3}{|c|}{ Isotropic $\mathrm{E}=1100 v=0.2$} \\
\hline Vaults infill & 1100 & \multicolumn{3}{|c|}{ Isotropic $\mathrm{E}=400 v=0.1$} \\
\hline Perimeter walls internal leafs & 1800 & \multicolumn{3}{|c|}{ Isotropic $\mathrm{E}=350 v=0.1$} \\
\hline Vaults hypostyle hall & 2000 & 5000 & 0.1 & 1200 \\
\hline
\end{tabular}

The direct comparison between the responses of the two different geometrical configurations is shown in Fig. (8) with reference to the first natural mode of vibration.

\subsection{Elastic analyses under gravity loads}

The action to which reference must be made in order to obtain a realistic evaluation of the safety conditions of the castle in terms of stresses is undoubtedly the weight. With the notable exception of the earthquakes, the contribution of the variable actions (e.g. wind and snow) is irrelevant, both as instantaneous effects and also when considering effects extended over time.

Here it is worth noting that, despite the fact that an elastic approach is adopted in the paper, masonry should be more accurately modeled by means of more sophisticated materi- als, e.g. with elasto-plastic with softening or damaging models, nowadays commonly available in commercial codes, but which would require a strong numerical effort for the incremental analyses. Similarly to the seismic case, an elastic approach in presence of gravity loads may furnish preliminary first information on the actual state of compression and on the zones which undergo relevant states of tensile stresses. Such method can provide (taking into account the limitations of the available data, especially when dealing with the survey and definition of the construction and mechanical characteristics of the vaulted system) important qualitative information for indicating the evolutionary trends of stress states present and identifying a possible global behavior that could be dangerous to the structural integrity, hence indirectly providing interesting information on the most critical zones which would require some rehabilitation interventions. 


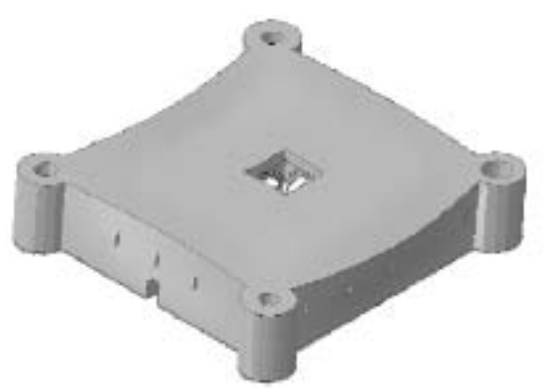

Mode I. Frequency $\mathrm{Hz} 5.37$

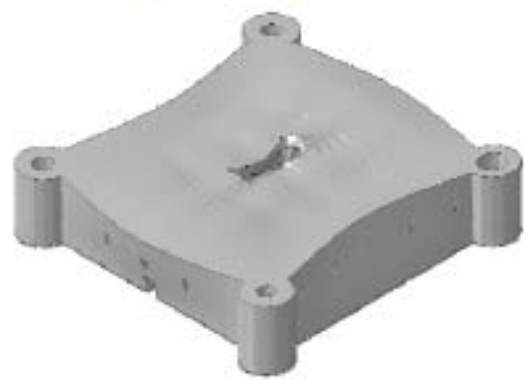

Mode III. Frequency $\mathrm{Hz} 6.08$

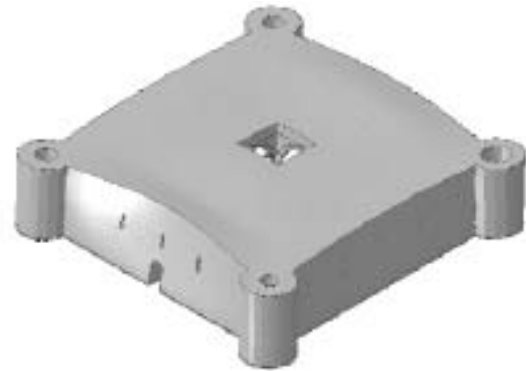

Mode II. Frequency $\mathrm{Hz} 5.40$

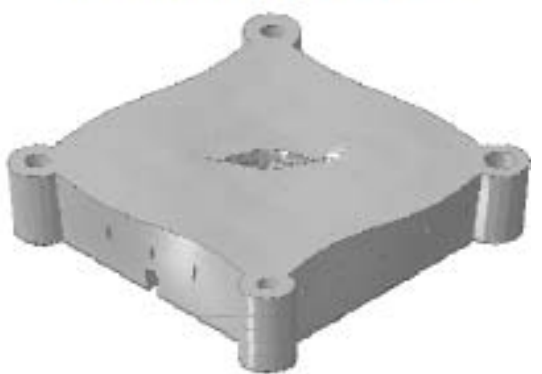

Mode IV. Frequency $\mathrm{Hz} 7.71$

Fig. (7). First four eigen-models and corresponding frequencies. Configuration after the hypothetical reconstruction of the original hypostyle room.
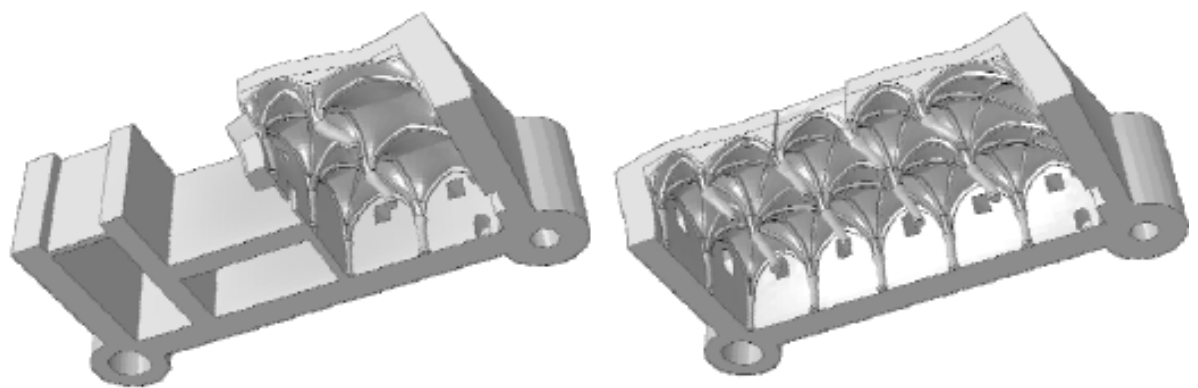

Fig. (8). Comparison of the first natural mode of vibration of the two meshes. Detail of the deformed shape in correspondence of the hypostyle hall.

Within this context, the numerical analyses point out signs of real critical conditions with particular attention to the safety conditions of the columns and the vaults. Some of the huge amount of numerical results provided by the static analyses under gravity loads are represented from Fig. (9) to Fig. (14). In particular Fig. (9)-Fig. (11) refer to the actual configuration (Mesh 1), whereas Fig. (12)-Fig. (14) to the castle in the hypothetical reconstruction of the original configuration. More in detail, in Fig. (9) and Fig. (12) the deformed shapes of Mesh 1 and Mesh 2 respectively are represented, whereas in Fig. (10) and Fig. (13) the vertical stress maps are depicted. Finally in Fig. (11) and Fig. (14) the maximum principal stress maps are reported. Such representations of stresses give an interesting insight into the peaks of compression which some zones of the castle are subjected and the areas where there is a particularly relevant value of tensile stress. These latter regions should exhibit in reality a coherent crack pattern. Conversely, deformed shapes provide interesting information on the state of deformation, especially at the base of the columns of the hypostyle hall.
As it is possible to notice from a detailed analysis of the results, the level of compression reaches values of around 5 MPa (4.60 for Mesh 1 and 5.80 for Mesh 2) in the central columns, in very good agreement with both experimental tests and previous numerical analyses conducted by different authors. Such a large value is partially justified by the considerable bending of such structural elements which can be noticed from the deformed shapes.

The values of compression of some of the columns should be considered with care. In particular, it is worth noting that the few data obtained in the laboratory tests on stone samples by different authors [1, 3], presumably of the same type as those used to build the columns, indicate compression strength values with a great scatter, with lower bounds near $10 \mathrm{MPa}$ (only twice the stress found for gravity loads). Furthermore, it is expected that the resistance of the columns could be even lower, being built using ashlar masonry. This may partially justify the vertical cracks present in the columns. 


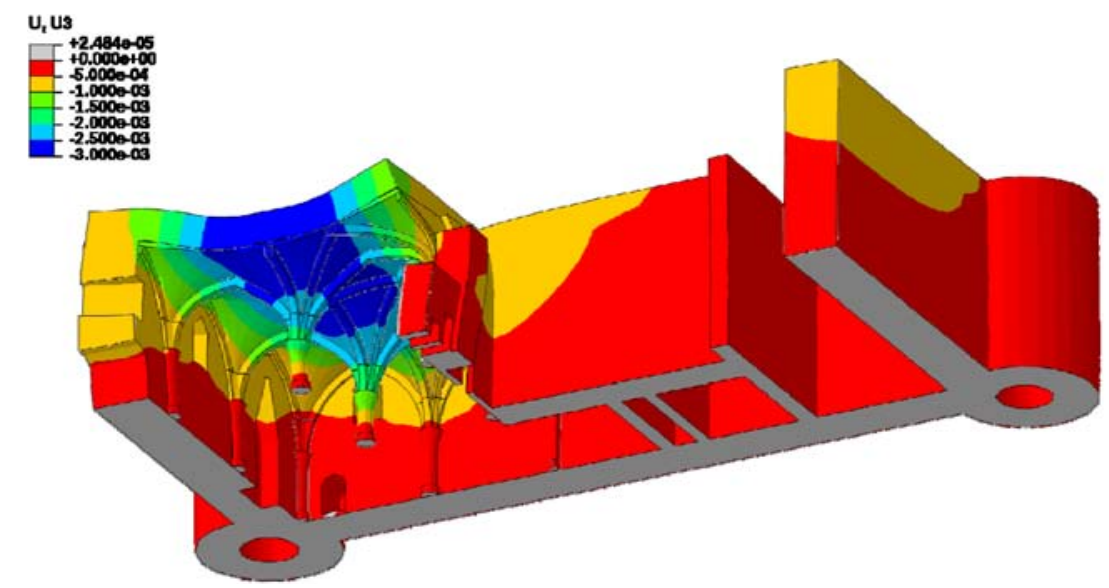

Fig. (9). Present configuration. Elastic Deformed shape of one half of the castle in the presence of gravity loads.

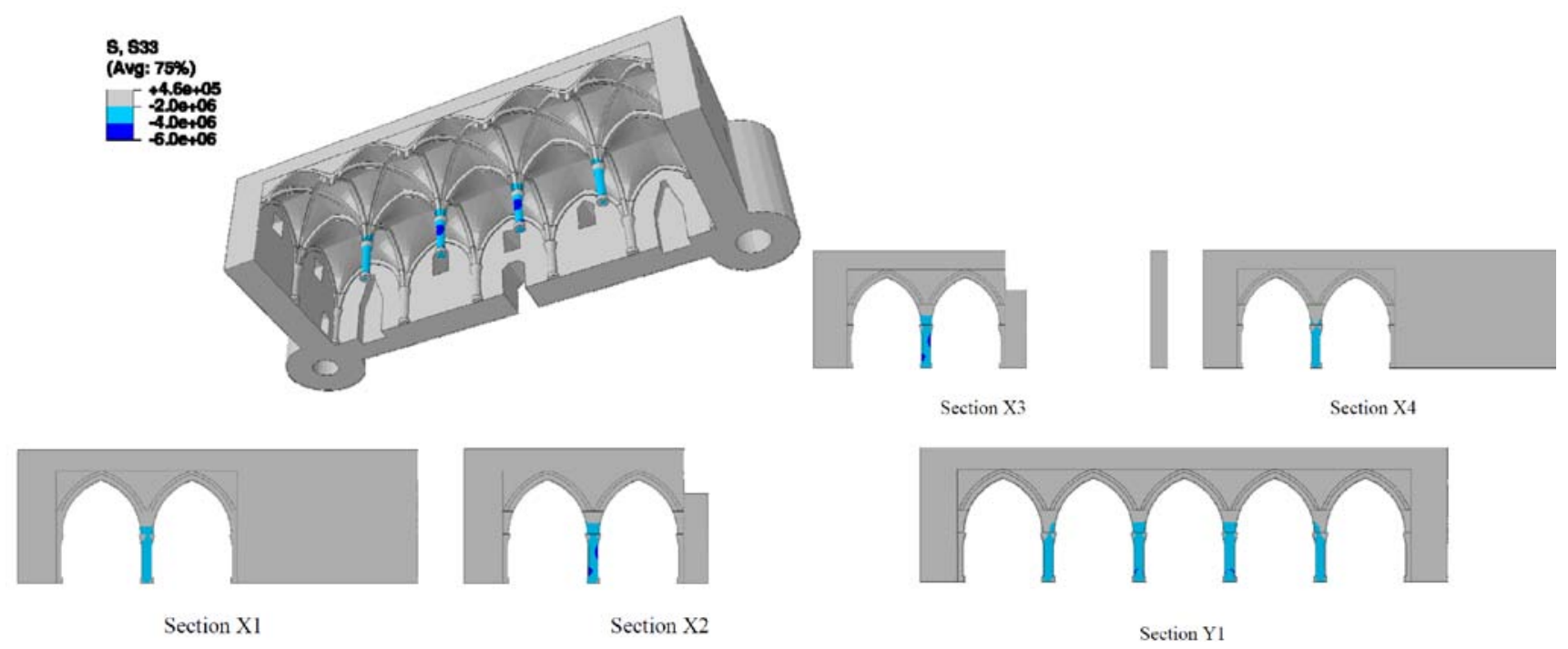

Fig. (10). Present configuration. Vertical stress (Pa) for gravity loads acting on elements belonging to the hypostyle hall.

In addition, it is expected that the seismic action on the columns entails, as an effect of a structural behavior that will be commented in the following section, a substantial increase of the eccentricity of the vertical load at the columns base, and a corresponding aggravating of the state of stress that the numerical analyses estimate in a significant partialization and an increase in the compression stress of around $40 \%$ (therefore bringing the maximum stress very close to the value of resistance obtained in the tests on samples of stone). Finally, non-destructive tests conducted by Modena and coworkers [2] indicated the existence of cracks (and/or voids or cavities) deep inside the most stressed parts of the columns, where lesions also appeared on the surface.

In the rest of the structure, the state of stress seems less critical, with concentrations found experimentally but sometimes not shown by the numerical analyses (e.g. in the south tower) and presumably connected to the effects of the explosion that partly destroyed the castle. All these aspects of degradation should be taken into consideration for planning structural upgrading interventions (e.g. injections, limited reconstruction).

To conclude, the columns of the hypostyle hall appear the most problematic elements of the castle. In the following section comments will be made on the aspects connected to the possible effects of seismic action, but independently of any work to improve the structural behavior of the monument as a whole. It is obvious that the possible hypotheses of specific reinforcement of the columns in relation to the stresses present under static loads must be seriously considered.

Other interesting considerations may be related to the very limited presence of a relevant state of positive principal stress, as shown in Fig. (11)) and Fig.(14) for the present situation and the original hypothetical configuration respectively. It is clear that the shape of the castle has been correctly designed to avoid the presence of tensile stresses due to the simple gravity weight.

\subsection{Static Analysis Under Horizontal Loads}

Static analyses under horizontal loads are performed along both $\mathrm{x}$ and $\mathrm{y}$ directions, see Fig. (3). Here, only results referred to direction y are reported since they are the more significant, and for the sake of conciseness. The choice of not performing a full spectral analysis is simply connected to the need of obtaining a mean to compare the responses of the two different geometrical configurations (Mesh 1 vs. Mesh 2 ), when subjected to horizontal loads, in the most clear 


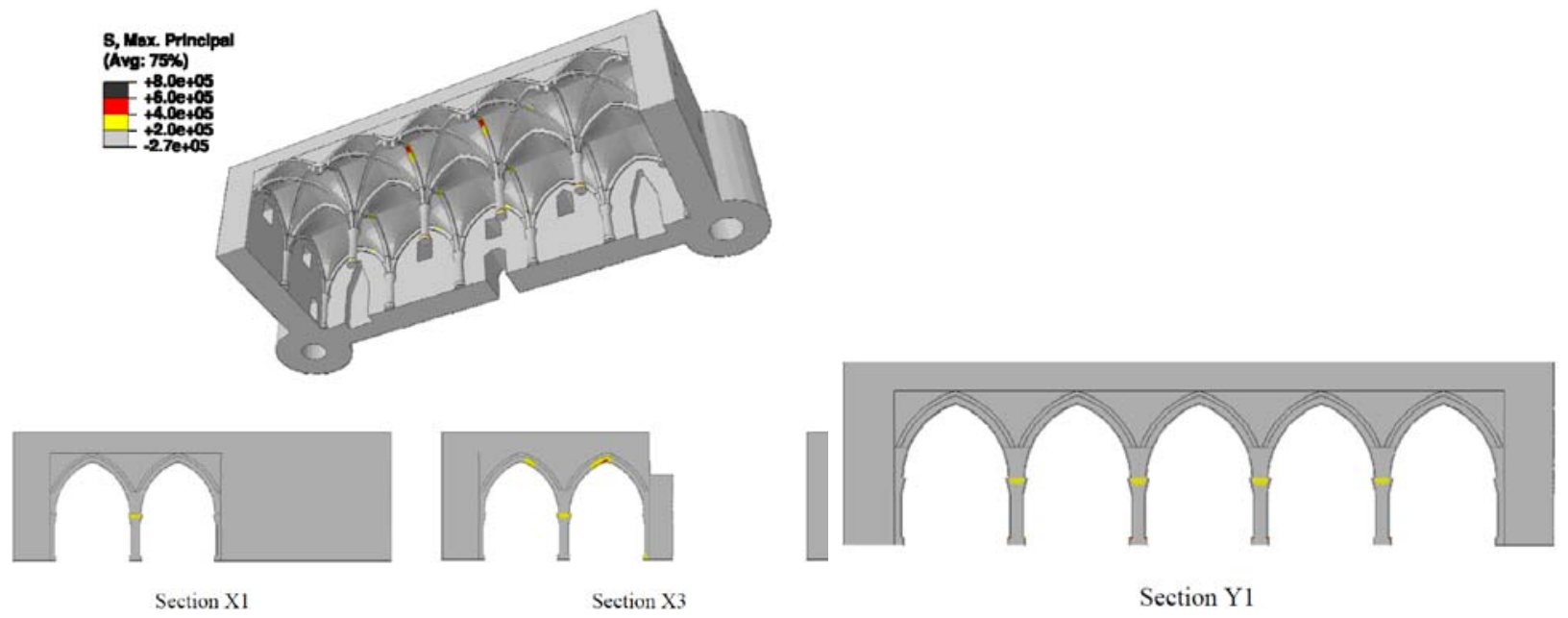

Fig. (11). Present configuration. Maximum principal stress (Pa) for gravity loads acting on elements belonging to the hypostyle hall.

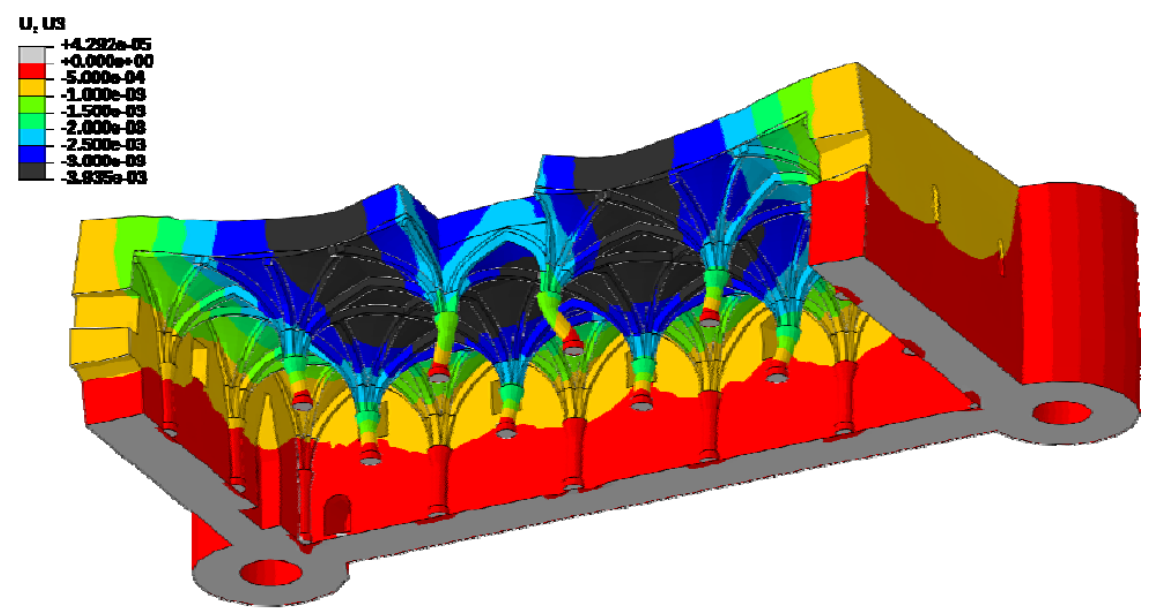

Fig. (12). Hypothetical reconstruction of the original configuration. Elastic deformed shape of the castle in presence of gravity loads.
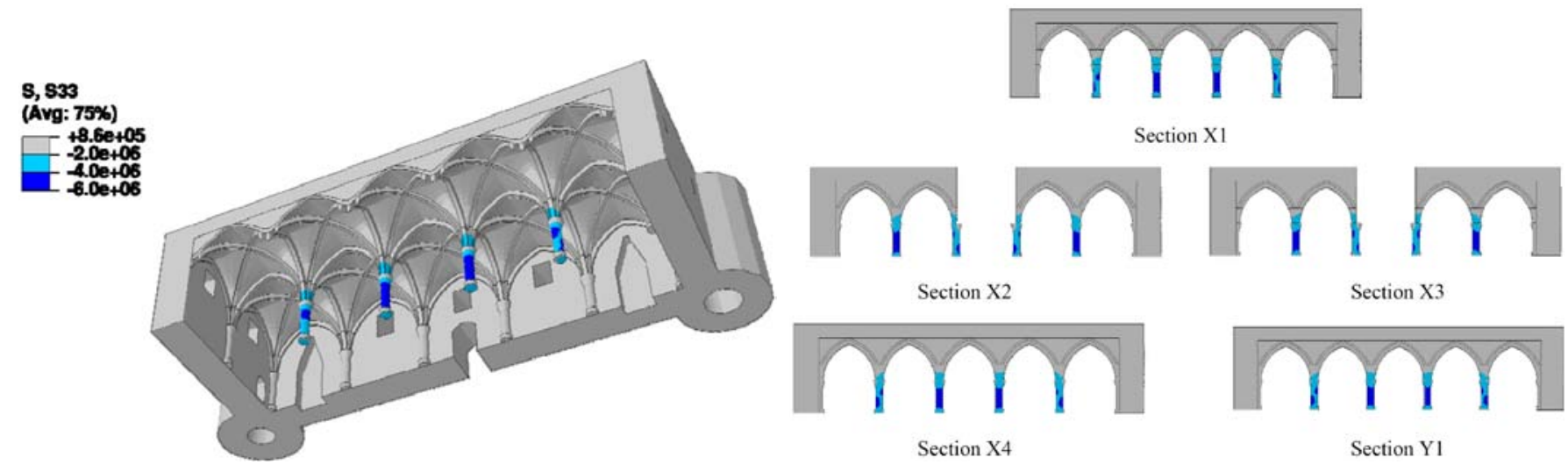

Fig. (13). Hypothetical reconstruction of the original configuration. Vertical stress (Pa) for gravity loads acting on elements belonging to the hypostyle hall.

manner and considering the fact this research is a very preliminary investigation of the 3D structural behavior of the complex hypothetical project of reconstruction of the complete hypostyle room. An effective seismic verification of the project is out-of the scope of the present study, while performing a detailed spectral analysis on a 3D FE model would be not automatically handled and therefore it is avoided here for the sake of simplicity.
In Fig. (15), deformed shapes of Mesh 1 and Mesh 2 when loaded with both gravity and horizontal loads are shown comparatively. Even from an undetailed analysis of the elastic deformed shapes, it is rather clear that the behavior of Mesh 2 is globally much more regular, but the local bending of the central columns remains critical and essentially unchanged with respect to the present situation. Conversely, the global behavior may be comparable to that exhibited 

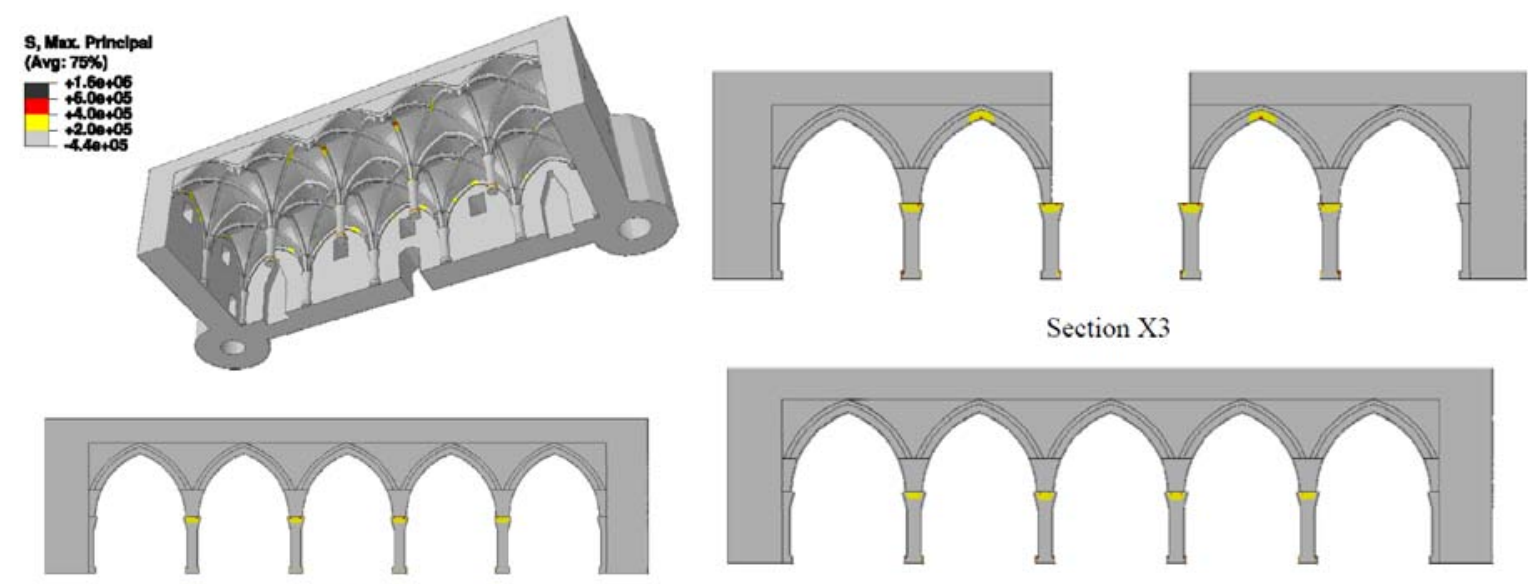

Section X3

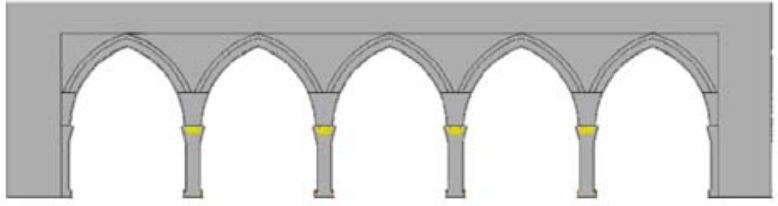

Section Y1

Fig. (14). Hypothetical reconstruction of the original configuration. Maximum principal stress (Pa) for gravity loads acting on elements belonging to the hypostyle hall.
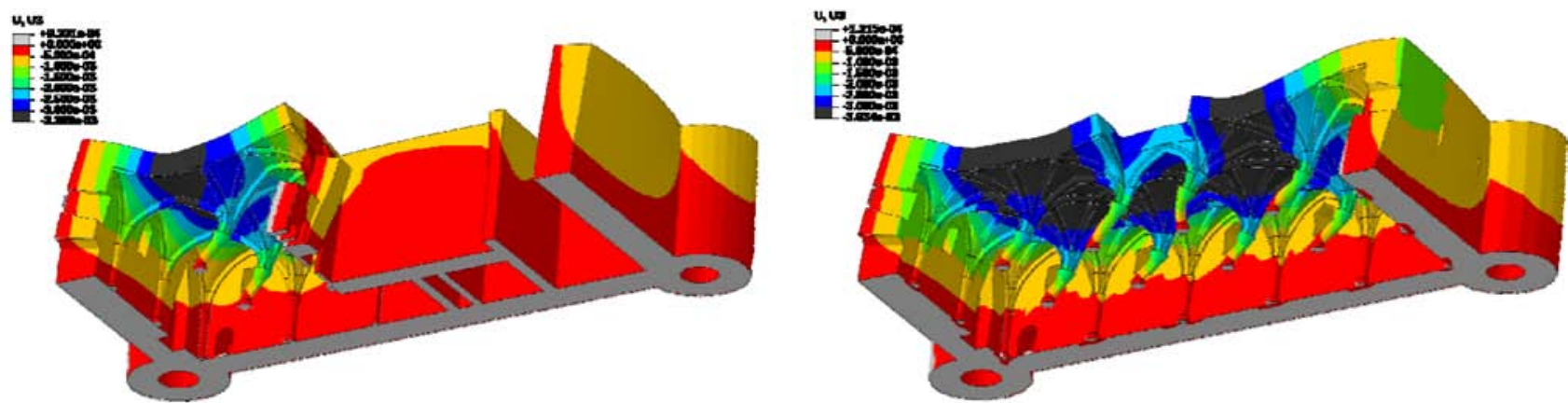

Fig. (15). Deformed shape for lateral load in $y$ direction. Left: present situation. Right: hypothetic reconstruction of the original configuration.

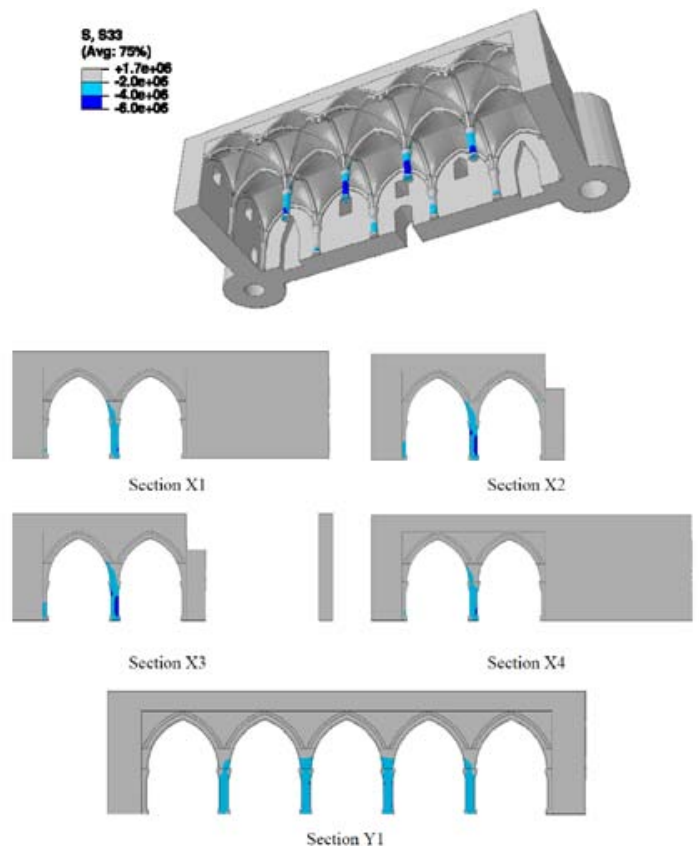

Fig. (16). Present configuration. Vertical stress S33 patch for lateral load in y direction (Pa), hypostyle hall.

by box buildings, with external walls providing the most important contribution in terms of stiffness and strength. Internal columns appear however again the most vulnerable part of the structure, especially the central ones. This is not surprising, since this is the zone where horizontal deformation concentrates. 

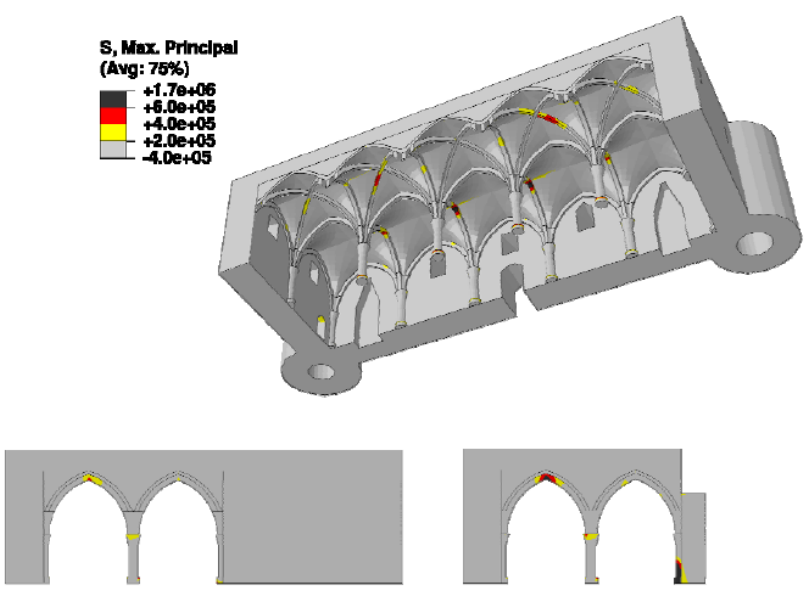

Section X1

Section X3

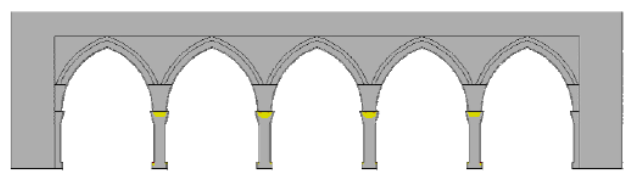

Section Y1

Fig. (17). Present configuration. Maximum principal stress (Pa) for lateral load in y direction, hypostyle hall.
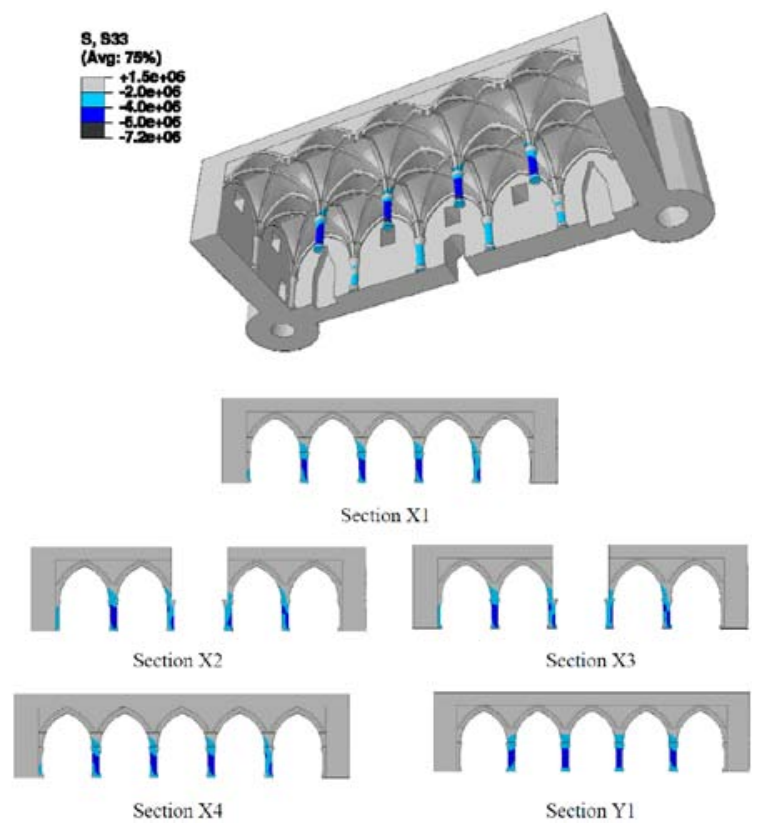

Fig. (18). Hypothetical reconstruction of the original configuration. Vertical stress S33 patch for lateral load in $y$ direction (Pa), hypostyle hall.

Results in terms of internal stresses are represented for the two models in Fig. (16-19). In particular, vertical stress S33 and maximum principal stress patches are depicted. While vertical stress gives an important insight into the state of compression of columns, maximum principal stress puts in evidence zones that could be critical with regard to the possibility of formation of cracks.

The static analyses under both horizontal and gravity loads highlight considerable peaks of compressions stress, close to the crushing values for good limestone in the central columns of the hall and in the buttresses, in both models.
Compression values increase in Mesh 1 from 4.60 MPa to around $6 \mathrm{MPa}$ when horizontal loads are applied and from 5.80 MPa to 7.20 MPa in Mesh 2, at the base sections of central columns, with a percentage increase near $30 \%$ in both cases. This is not surprising, since central columns bend considerably when a horizontal load is applied. The contemporary presence of vertical pre-compression and considerable bending results into a strong partialization of the section at the base, with the consequent increase of stresses in the compressed region. Bending was present in the central columns even for gravity loads only. The model corresponding to the original hypothetic configuration of the castle provides 

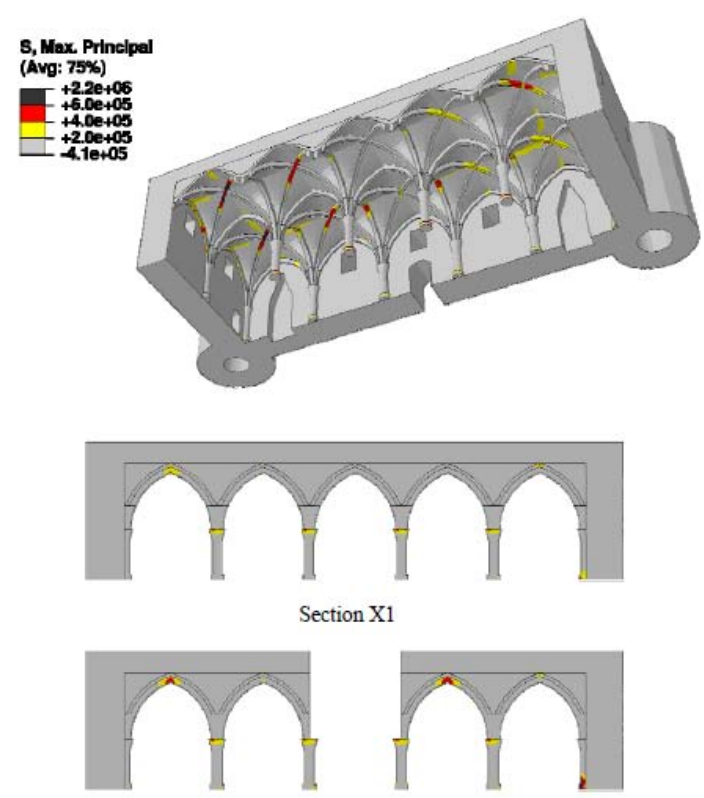

Section X3

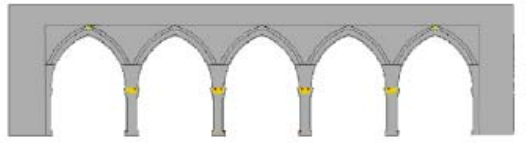

Section Y1

Fig. (19). Hypothetical reconstruction of the original configuration. Maximum principal stress (Pa) for lateral load in $y$ direction, hypostyle hall.

nearly the same results, but with slightly increased peaks, meaning that the behavior under seismic loads of the castle in its original configuration has a similar performance with respect to the castle as it appears nowadays.

Analogously to what observed in presence of gravity loads only, positive principal stresses Fig. (17 and Fig.19) exceeding masonry tensile stresses are present in both models in limited regions of the vaults and at the top of the arches. Again, as expected, the horizontal load results into a spreading of such critical zones, meaning that a diffusion of cracks on vaults is expected in case of seismic event. Regarding the spread of areas subject to significant levels of principal tensile stress, however, we notice that the configuration with the hypothetical reconstruction of the vaulted hall (Mesh 2) seems to perform better than what meets the current configuration (Mesh 1). This is evident if we look at the map of reported principal tensile stress for section X3 of Fig. (17) and Fig. (19). This leads us to think that probably the overall seismic behavior of the castle could benefit from having a fully symmetric geometry. This observation, however, will be further verified by means of dynamic analysis and possibly also in the non-linear field.

To establish quantitatively if the application of a horizontal load will result into the collapse (partial or total) or the vaults belonging to the hypostyle hall for the activation of a failure mechanism in correspondence of the cracks (regarded as plastic hinges), a full 3D limit analysis of the "Salone" by means of consolidated non commercial homogenized limit analysis codes $[12,13,17]$ is planned by the authors. The evaluation of a non-invasive local strengthening obtained applying at the extrados of the vaults CFRP strips is also under investigation. In particular, both strips optimal disposition and the effect in terms of increase of the load carrying capacity of the vaults will be investigated.

\section{CONCLUSIONS}

Two numerical models for the structural analysis of the Maniace Castle in Syracuse, Italy, before and after restoration have been presented. While the models are fully elastic and the analyses are performed with the commercial code ABAQUS, some interesting insights into the actual behavior of the castle in the presence of gravity loads and seismic action may be provided. When dealing with gravity loads analyses, even elastic numerical models may be able to provide quite accurate results as far as the vertical compression stress is investigated. Conversely, the state of maximum principal stresses provides a suggestive picture of the zones where tensile cracks, most probably, concentrate. From simulations results, it appears clear that there is a critical static situation at the base of the columns belonging to the hypostyle hall, especially in the central part. The state of compression is very near to the experimentally determined strength of such structural elements, especially near the base. A meaningful state of traction is also diffused at the top of the vaults, but this appears quite normal for such typology of traditional double curvature elements, since even gravity loads result in considerable bending of the vaults. An inter-vention reporting the castle into its original configuration would have, globally, little effect regarding the state of stress of the columns for gravity loads, with a slight increase of the peaks. This is largely expected, since in the hypothetical original 
configuration the hypostyle hall geometry remains essentially unchanged. The remaining three sides would host three new halls conceived by the same architectural system of the existing hypostyle hall, thus making the castle fully symmetric, but essentially exhibiting the same static response of the existing hall. Such symmetry, on the contrary, helps in a more monolithic behavior of the castle under horizontal loads (seismic analysis) with a reduction of the vaulted areas subjected to tensile principal stress, as well as with a globally better response in terms of eigenvalue analyses. Local strengthening intervention should be planned for the existing columns belonging to the hypostyle hall, whereas the newly constructed columns should be conceived with a material with better quality in terms of resistance.

\section{CONFLICT OF INTEREST}

The authors confirm that this article content has no conflicts of interest.

\section{ACKNOWLEDGEMENT}

Declared none.

\section{REFERENCES}

[1] "Castello Maniace - Siracusa, Indagini diagnostiche sulle strutture murarie", Tech. Memo, ISMES (Enel Group), Italy. 1999 [in Italian].

[2] C. Modena, P. Franchetti, D. Zonta, R. Menga, E. Pizzigalli, F. Ravasio, M. Muti, R. Meloni, and G. Bordone, "Static and dynamic analyses of Maniace Castle in Siracusa-Sicily”. In: Historical constructions, Ed P.B. Lourenço and P. Roca, Guimaraes: Portugal, pp. 933-943, 2001.

[3] "Indagini strutturali sulle murature del Castello Maniace", Tech. Memo, Ipertec srl., Italy. 2003 [in Italian].

[4] S. Casolo, V. Petrini, and C.A. Sanjust, "Lo studio di interventi antisismici tramite analisi dinamiche con un modello ad elementi rigidi: il caso del Castello Maniace", Ingegneria Sismica, vol. 3, pp. 36-43, 2007.

[5] S. Casolo, and C.A. Sanjust, "Seismic investigation on the cathedral of Syracuse by finite elements and by a specific rigid body and spring model" In: $10^{\text {th }}$ International Conference on Structural Stud- ies Repairs and Maintenance of Heritage Architecture STREMAH, C.A. Brebbia, Ed. WIT Press, Prague: Czech Republic 2007.

[6] S. Casolo, and C.A. Sanjust, "Seismic analysis and strengthening design of a masonry monument by a rigid body spring model: the Maniace Castle of Syracuse", Eng. Struct., vol 31, pp. 1447-1459, 2009.

[7] G. Maggioni, "Il castello Maniace di Siracusa", PhD Thesis, Politecnico di Milano [in Italian], 2009.

[8] Hibbitt, Karlsson \& Sorensen, Inc. "ABAQUS manuals”, version 6.5, 2005.

[9] V. Mallardo, R. Malvezzi, E. Milani, and G. Milani, "Seismic vulnerability of historical masonry buildings: a case study in Ferrara", Eng. Struct., vol. 30, no. 8, pp. 2223-2241, 2008.

[10] P.B. Lourenço, G. Milani, A. Tralli, and A. Zucchini, "Analysis of masonry structures: review of and recent trends in homogenization techniques", Can. J. Civ. Eng., vol. 34, no. 11, pp. 1443-1457, 2007.

[11] Italy. Ministero delle Infrastrutture, "NTC 2008. Nuove norme tecniche per le costruzioni", Gazzetta Ufficiale, vol. 29, 2008.

[12] G. Milani, E. Milani, and A. Tralli, "Limit analysis of masonry vaults by means of curved shell Finite Elements and homogenization", Int. J. Solids Struct., vol. 45 no 20, pp. 5258-5288, 2008.

[13] G. Milani, E. Milani, and A. Tralli, "Upper Bound limit analysis model for FRP-reinforced masonry curved structures. Part II: structural analyses", Comput. Struct., vol. 87 no. 23-24, pp. 1534-1558, 2008.

[14] Italy. Presidenza del Consiglio dei Ministri, "O.P.C.M. 3274 20/03/2003 \& O.P.C.M. 3431/05, 09/05/2005", First elements concerning general criteria for the seismic classification of the national territory and technical norms for structures in seismic zone [in Italian], 2003, Further modifications and integrations on OPCM 3274/03 [in Italian], 2005.

[15] Italy. Presidenza del Consiglio dei Ministri, "DPCM 2007 Direttiva del Presidente del Consiglio dei Ministri 12 ottobre 2007 per la valutazione e la riduzione del rischio sismico del patrimonio culturale con riferimento alle norme tecniche per le costruzioni.", Gazzetta Ufficiale, vol. 24, 2008.

[16] Italy. Presidenza del Consiglio dei Ministri, "DPCM 2011 Direttiva del Presidente del Consiglio dei Ministri 09.02.2011 per la valutazione e la riduzione del rischio sismico del patrimonio culturale con riferimento alle norme tecniche per le costruzioni DM 14.01.2008.", Gazzetta Ufficiale, vol. 47, 2011.

[17] G. Milani, K. Beyer, and A. Dazio, "Upper bound limit analysis of meso-mechanical spandrel models for the pushover analysis of 2D masonry frames", Eng. Struct., vol. 31, pp. 2696-2710, 2009.

(c) Casolo et al.; Licensee Bentham Open.

This is an open access article licensed under the terms of the Creative Commons Attribution Non-Commercial License (http://creativecommons.org/licenses/by-nc/3.0/) which permits unrestricted, non-commercial use, distribution and reproduction in any medium, provided the work is properly cited. 